\title{
Flash flood impacts nowcasting within the PICS project (2018-2022): End- users involvement and first results
}

Pierre Javelle ${ }^{1}$, Olivier Payrastre ${ }^{2}$, Brice Boudevillain ${ }^{3}$, François Bourgin ${ }^{4}$, François Bouttier ${ }^{5}$, Olivier Caumont ${ }^{5}$, Maryse Charpentier-Noyer ${ }^{2}$, Veronique Ducrocq ${ }^{5}$, Axelle Fleury ${ }^{5}$, Pierre-André Garambois ${ }^{1}$, Eric Gaume ${ }^{2}$, Nabil Hocini ${ }^{2}$, Bruno Janet ${ }^{7}$, Maxime Jay-Allemand ${ }^{1}$, Dimitri Lague ${ }^{8}$, Alexane Lovat ${ }^{5}$, David Moncoulon ${ }^{6}$, Jean-Philippe Naulin ${ }^{6}$, Pierre Nicolle ${ }^{2}$, Daniela Peredo $^{4}$, Charles Perrin ${ }^{4}$, Frédéric Pons ${ }^{9}$, Maria-Helena Ramos ${ }^{4}$, Isabelle Ruin ${ }^{3}$, Galateia Terti ${ }^{3}$

${ }^{1}$ INRAE, UR RECOVER, 3275 route Cézanne - CS 40061, 13182Aix-en-Provence Cedex 5, France

2 Université G. Eiffel, Geotechnical engineering, environment and risks, Bouguenais cedex, France

${ }^{3}$ Université Grenoble Alpes Institut des Géosciences de l'Environnement (IGE), CS 40 700, 38058 Grenoble cedex 9 , France

${ }^{4}$ INRAE, UR HYCAR, 1, ruePierre-Gilles de Gennes, CS 10030, 92761 Antony Cedex, France

${ }^{5}$ CNRM, 42 Av G.Coriolis, 31057 Toulouse Cedex, France

${ }^{6}$ CCR, 157, Boulevard Haussmann 75008 Paris, France

7 SCHAPI, 42, avenue Gaspard Coriolis, 31057 Toulouse Cedex 01, France

${ }^{8}$ Université Rennes 1, Géosciences Rennes, Campusde Beaulieu, 35042 Rennes Cedex, France

${ }^{9}$ Cerema, Direction Méditerranée, 30 rue Albert Einstein, 13593 Aix-en-Provence, France

\begin{abstract}
Flash-flood events can have catastrophic socio-economic consequences. To reduce their impacts, it is of crucial importance to set up efficient warning systems. Although first operational flash-flood warning systems have recently been implemented, some limitations are clearly identified by end-users: non-exhaustive geographic coverage, limited lead times, warnings based on hazard assessment instead of risk. However, the desirable improvements raise real scientific challenges in various domains. In this context, the PICS (Prevision immediate des impacts des crues soudaines - Flash-flood events impacts nowcasting - 2018-2022) project gathers French scientific teams with varied skills (meteorologists, hydrologists, hydraulicians, economists, social geographers) and operational stakeholders (civil security, local authorities, insurance companies, managers of hydroelectric facilities and transport network). Funded by the French national research agency (ANR), it aims to develop and evaluate pre-operational forecasting chains able to estimate the potential impacts of flash floods with short anticipation lead times (up to 6 hours). These modelling chains include different components. Distributed hydrological models transform the observed and forecasted rainfall into runoff. Hydraulic models translate this runoff into potential flooded areas. Impact models incorporate these results to evaluate the potential for social and economic impacts. The research and operational partners selected four case studies based on various criteria, including the occurrence of human impacts and damages, the availability of validation data. Validation data include discharges recorded at gauging stations, but also more original information collected after each event, such as peak discharges and maximum water levels estimated from flood marks, insurance claims, damages observed on infrastructure (roads, railway...), victims interviews, casualties, etc. This presentation focuses on the methodology used for the involvement of representative potential end-users, leading to fruitfull dialogues and informative outcomes. Some of the first results of the project are also presented.
\end{abstract}

\section{Introduction}

Affecting 2.3 billion people over the 1995-2015 period, floods are the first weather-related disaster in the world (CRED and UNDRR, 2015). In France, 1 inhabitant over 4 is exposed to this hazard (MEDDE, 2012), and over the 19822019 period, inundations represented in term of insured costs 21 billion of euros, i.e. $55 \%$ of the total costs of all natural

${ }^{a}$ Corresponding author: pierre.javelle@,inrae.fr

DOI 10.3311/FLOODRisk2020.17.3 disasters (CCR, 2019). With global warming and its consequences (IPCC, 2018), insurance companies even estimate that flood-related impacts will more than triple by the end of the century (Munich RE, 2018).

In this context, as noted in the Sendai Framework for Disaster Risk Reduction (DRR) 2015-2030 (United Nations, 2015), effective early flood warning systems are crucially needed, both for immediate crisis management and also to strengthen society resilience. Such systems have to perform accurate flood forecasts in terms of location, magnitude and 
timing, but also to identify areas "at risk", i.e. prone to trigger fatalities and economic losses.

Flash flood forecasting requires integrated chains coupling meteorological and hydrological models (Collier 2007, Hapuarachchi et al. 2011). Operational systems used all over the world now combine radar rainfall information and distributed hydrological models (Javelle et al., 2016, Gourley et al. 2017, Anderson et al. 2019, Corral et al., 2019). Furthermore, Numerical weather prediction (NWP) models are now able to reproduce heavy precipitation at kilometre resolutions for typically 6 to 48 -h lead time (see for example in France the AROME model, Sauvage et al., 2020). For short term prediction $(0-3 \mathrm{~h})$, generating different stochastic scenarios based on the latest radar observations is an effective way to estimate forecast uncertainties: as for example in the STEPS method (Seed et al. 2013), the SBMcast method (Berenguer et al. 2011), the stochastic extension of the MAPPLE method (Atencia and Zawadzki 2014, 2015), or the SAMPO-TBM method (Caseri et al. 2016ab).

However, forecasting Mediterranean flash floods caused by sudden, intense and localized thunderstorms (for example in Cannes in 2015, 175-mm of rainfall fallen in only 2 hours causing huge damage), remains a tricky challenge. NWP models still have difficulties to anticipate and to localize properly intense convective cells. Furthermore, hydrological and hydraulic models are strongly impacted by the lack of calibration data on small watersheds hit by flash floods. And finally, hazard mapping, exposure, and risk assessment are also rarely available. In this context, the "Prévision Immédiate Intégrée des Crues Soudaines" (PICS) project brings together modellers from different fields (meteorologists, hydrologists, hydraulicians and sociologists), and decision makers involved in crisis management, to experiment new generations of flash flood forecasting chains, aiming both at improving anticipation and enabling a better representation of impacts of the forecasted floods.

The PICS project tried to initiate a fruitful dialogue with a panel of potential end users, offering opportunities to share experiences and new ideas. For this purpose, continuous exchanges have been organized with a so-called "end users group", to provide a regular feedback about the project objectives, the developments in progress and the final results. The main aim of this paper is to present both the methodology used to exchange with the end users group, and the main results of these interactions.

The paper is divided in two parts. The first part explains the methodology used to involve potential end users and stimulate useful exchanges along the project. The second part presents the main feedbacks gathered from end users and some first project results.

\section{Organization of exchanges with the end users group}

A fruitful dialogue with potential end-users is obtained in the project through regular workshops gathering during one day at the same place the end users group and all project contributors. Different activities are alternatively proposed: plenary "classical" presentations enable to expose end users specific needs and opinions or project ongoing developments; then, sub-group discussions are organized to stimulate interactions between all participants and define common orientations.

Those workshops have been planned at different stages of the project: a first one 6-month after the start of the project (in May 2018), a second one at the mid-term (in December 2019) and a final one at the end of the project (to be held in 2022).

The next following paragraphs present the composition of the end users group, and the specific objectives of the three organized workshops.

\subsection{A representative and varied end users group}

The end users group has been formed at the early beginning of the project. It initially included eleven members but has continuously grown to reach now 23 members. This group has been formed to well represent all sensitivities of operational contributors to flash flood risk management. The represented end users can be grouped in five main categories.

- State authorities having in charge crisis coordination and preparedness

- DDTM de l'Aude (mission RDI)

- Mission Arc Méditerranéen

- Ministère de l'Intérieur/DGSCGC

- Local authorities in charge of crisis management and rescue operations

- Municipalities: Ville de Cannes, Ville de Nîmes, Nîmes métropole

- River basin management structures: Syndicat d'Aménagement du Bassin de l'Arc (SABA), Syndicat Mixte de l'Argens, Syndicat Mixte des Milieux Aquatiques et des Rivières, EPTB de l'Aude (SMMAR),

- Fire services: SDIS $(11,13,30)$

- Local authorities and/or private companies providing forecasts or support tools to the other actors

- Local flood forecasting authorities: (Méditerranée-Est, Grand-Delta, Méditerranée-Ouest and Seine-Moy.-YonneLoing), being part of the national Vigicrues network

- Private companies providing assistance to municipalities: Predict services, Novimet, Hydris Hydrologie

\footnotetext{
- Private operators having in charge a national or regional critical infrastructure

- CNR (electricity producer on the Rhône River)

- EDF-DTG (electricity national producer)
} 
- SNCF Réseau (national railway)

- Insurance companies having in charge the financial compensations

- Axa Global P\&C

- Willis Re

\subsection{First workshop: defining needs and potential case studies}

The first workshop helped to define the frame of the whole project: what are exactly the needs and how can we meet them? In that aim, attending end users were invited to present their own problematic, their current practices, the main current limitations they identify, and the main progress they would like the project to contribute to in this domain. Then, they were invited to discuss in small groups, including the project contributors, to share their experiences and try to define first common reasonable objectives. The main outcome of these exchanges finally helped to define the priorities in the developments to be achieved during the project.

This workshop also helped to identify a panel of recent critical events, for which currently available information tools showed clear limitations. Those events should be well documented in term of observations and hindcasts, but also in terms of available validation datasets. This data includes information on peak discharges (obtained if necessary from post event surveys), on the extent of observed flooded areas, and also all kind of useful information for the characterization of impacts (submersion of roads, habitations, social media, etc.) and of the events dynamics and timing.

2.3 Second workshop: collecting feedbacks on project progress and defining further developments

During the second workshop, the project contributors presented different components of the future forecasting chains they were developing and aiming to fulfil the needs identified in the first workshop. End users were invited to give their feedback on those different developments, based on some issues raised by the project contributors. Finally, end users were asked to work in small groups to define more precisely how they would like to see those different components chained in an integrated forecasting system. This helped to customize the different tests and developments to be carried out during the two last years of the project, i.e. the structures of the forecasting chains to be experimented for the selected case studies.

\subsection{Final workshop: evaluating the usefulness and limits of the developed forecasting chains}

This very last workshop will occur at the end of the project (mid 2022). It will consist in evaluating with the end-users the results of the integrated forecasting chains experimented during the project. Benchmark evaluations will be used to evaluate the benefit of the new tested chains. The

${ }^{a}$ Corresponding author: pierre.javelle@inrae.fr

DOI 10.3311/FLOODRisk2020.17.3 exchanges should also take the form of a serious game illustrating the added value of the new real time information provided.

\section{First feedbacks obtained from end- users, and first project results}

\subsection{End users needs}

During the first workshop the end users could express their current needs and expectations for improved flash flood forecasting chains. The needs which were initially expressed can be summarized as follows for the different end users categories:

Insurance companies. This category identified a need of hazard and damage mapping (ideally in terms of costs), covering all the France at a high resolution, in real time or « small delayed » time, in order to improve their potential of reactivity during and just after an event. The main issue for these end-users is to be able to anticipate a huge number of claims, and to adequately allocate qualified experts. Clearly the accuracy and resolution of information has a larger importance than anticipation for this category.

Critical infrastructure operators. These actors also identified a need for detailed (high resolution) information over large areas (i.e. areas covered by their infrastructures). But for them, improving anticipation appears more important than describing impacts. They clearly highlighted the need for a sufficient lead time in order to take proper adaptation measures to protect the infrastructures. These decisions may have large economical costs (i.e. stopping the railway traffic) and can therefore be very difficult to take. Furthermore, some operators mentioned a clear interest in feeding their own actual forecasting system with short time probabilistic rainfall forecasts to properly represent uncertainties.

Local flood forecasting centres also outlined a need for improving rainfall forecasts at very short lead times (0 to 6h). Improving lead times by reference to current operational monitoring systems seems to be critical for this category of end-users in order to correctly manage flash flooding situations.

Local authorities in charge of crisis management and rescue operations expressed also a concern on short range forecasts. But they also stressed difficulties in translating current warnings (i.e. issued by the national vigilance system) in terms of field impacts. They expressed the need to know in advance where to position appropriate resources for crisis management.

\subsection{Project common objectives}

At the end of the first workshop, all actors agreed that fully chained forecasting tools, from weather forecast to impact estimates, currently do not exist and would probably facilitate their missions. After sub-groups discussions followed by a 
vote, the main common objectives they chose to assign to these forecasting chains were the following:

- Involvement of probabilistic rainfall forecasts for short (3h) lead times, and enabling high frequency updates (from 15 minutes up to $1 \mathrm{~h}$ );

- Improvement of spatial resolution of discharge and hazard forecasts to represent risks related to very small watercourses;

- Incorporate a representation of inundated areas and/or damage levels, in real or shortly-differed times, with a particular attention to accuracy and representation of uncertainties.

\subsection{Selection of case studies and validation data}

Figure 1 presents the different domains and events finally selected, which include some proposals expressed during the first end-users workshop. All the major flash floods occurred in France in the last years are included. Impacts validation data is available for most of these events, from different public sources such as the HYMEX database (Amponsah et al, 2018) or DAMAGIS database (Saint-Martin et al., 2018). It should be mentioned that the events of October 2018 (in particular on the Aude river) occurred after the first workshop and were added to the initial list. For those 2018 events, impacts validation data were collected from post-event field surveys carried out by the project contributors.

\subsection{Components to be coupled in integrated forecasting chains}

During the second workshop, project contributors illustrated with specific examples some of the on-going developments. Four groups of methods that need to be coupled were presented separately. The first group consists in providing rainfall radar observation and (ensemble) rainfall short range forecasts. The second group includes calibrated (semi-) distributed rainfall-runoff models. The third group involves 1D and 2D hydraulics models, in order to map potentially flooded areas. The last group develops different approaches to estimate the impacts, at different scales and for different purposes. The main outcomes of these exchanges with end users were the following:

Rainfall forecasting: End users agree that large ensembles are interesting because they make it possible to better estimate rare probabilities in automated chains. However, for very-short term forecasts, ensembles can be difficult to analyse. End users would like to "track" in real time the different scenarios in order to know which one is becoming "the most probable". In the case of decisions that can be taken at a longer lead time (for example to organize internal resources before a weekend), fully probabilistic forecasts are nevertheless useful to issue some internal "pre-alerts".

Rainfall-runoff modelling: Having realistic information at very high spatial and temporal resolutions is of great importance, and end users would like to get information for very low upstream drainage areas. For instance, in the case of railway network, many incidents are due to very small catchments $\left(<5-\mathrm{km}^{2}\right)$. Unfortunately, those scales appear to be at the current limits of predictability of rainfall-runoff modelling, but progress in 2-D hydraulic modelling directly fed with rainfall information and new available terrain (bathymetric and topographic) data offer good opportunities to fill this gap.

Inundation mapping: It appears that real time inundation computations do not necessarily correspond to a crucial need. Some pre-computed inundations scenarios could be rather used and recognized in real time for crisis management purposes, as already suggested by Le Bihan et al. (2017). This offers the double advantage to limit the delivery time of forecasts, and to give the opportunity for operational services to get prepared to the different possible inundation scenarios. If inundation mapping is not needed in advance, but just in the hours following the event (for instance for insurers), then there is an interest to re-run hydraulic models in shortdiffered time, to get more accurate results.

Impact modelling: Multi-agents modelling seems promising to properly represent the behaviour of individuals facing an inundation event. But as for the question of inundation mapping, implementing this kind of complex tools in real time does not appear as necessary. They can rather be used in differed time to help defining what/how/when to communicate to the public during the crisis, based on realistic scenarios. Alternatively, synthetic impacts indicators can be easily computed in real time based on forecasted inundation scenarios, to provide first useful information on the intensity of possible impacts.

\subsection{Illustration of the experimented forecasting chains}

Figure 2 presents how the different modelling components will finally be chained to form integrated flash flood forecasting chains, based on the proposals of end users gathered at the end of the second workshop. These forecasting chains are now being experimented on the case studies. Some of the different modelling components have been (or are currently) carried out by five $\mathrm{PhD}$ students involved into the project:

- Lovat et al. (2019, in review) focused on coupling different rainfall forecasts (AROME-PI, PIAF) with the hydrological ISBA-Topmodel;

- Jay-Allemand et al. (2020) developed a new method for spatially calibrating a distributed rainfall-runoff model (SMASH);

- Peredo (2021) assessed the quality of three recently developed ensemble forecasts products (AROME-PE, PEPI, pertDPEPI) on the adapted GRSDi semidistributed hydrological model (including a dependency on rainfall intensity in the production rate function, Peredo et al., 2021);

- Hocini et al. (2021) are developing automated inundation mapping methods to efficiently compute catalogues of 
inundation scenarios which may be sampled in real time (Floodos 2D, Cartino 1D);

- $\quad$ and finally, a last PhD student (Charpentier-Noyer et al., 2021) is currently investigating the interest of a whole ensemble forecasting chain, from rainfall to impacts.

As a first illustration of results provided by integrated forecasting chains, Figure 3 presents simulation results obtained by combining rainfall ANTILOPE reanalysis, the Cinecar hydrological model, the CARTINO-1D inundation model and the economic damage model of CCR (Fig. 2), for the 2018 event in the Aude river region. Validating with observed damage is ongoing, but this example illustrates the kind of results the future forecasting chains could provide.

\section{Conclusions}

The aim of the PICS project is to develop integrated flash flood forecasting chains, from rainfall to impacts, both for immediate crisis management and also to strengthen post flood resilience.

The strong end-users involvement at different stages of the project led to a fruitful dialogue, which helped to define the global objectives of the project and to gather feedbacks on realized or planned developments, including short term (ensemble) rainfall forecasting, hydrological modelling, inundation mapping and impact assessment.

Those developments are still on-going and a final common workshop will enable evaluating the usefulness and limits of forecasting chains that will be finally developed.

\section{Acknowledgement}

This research has been supported by the "Agence nationale de la recherche" (ANR-17-CE03-0011). Authors also thank the end users group for its participation to the organized workshops.

\section{References}

1 Amponsah, W. et al. (2018) Integrated high-resolution dataset of high-intensity European and Mediterranean flash floods, Earth System Science Data, 10(4), pp. 1783-1794. https://doi.org/10.5194/essd-10-1783-2018.

2 Anderson, S. R. et al. (2019) Towards operational joint river flow and precipitation ensemble verification: considerations and strategies given limited ensemble records, Journal of Hydrology, 577. https://doi.org/10.1016/j.jhydrol.2019.123966.

3 Atencia, A. and Zawadzki, I. (2014) A comparison of two techniques for generating nowcasting ensembles. Part I: Lagrangian ensemble technique, Monthly Weather Review, 142(11), pp. 4036-4052. https://doi.org/10.1175/MWR-D-13-00117.1.

${ }^{a}$ Corresponding author: pierre.javelle@inrae.fr

DOI 10.3311/FLOODRisk2020.17.3
4 Atencia, A. and Zawadzki, I. (2015) A comparison of two techniques for generating nowcasting ensembles. Part II: Analogs selection and comparison of techniques, Monthly Weather Review, 143(7), pp. 2890-2908. https://doi.org/10.1175/MWR-D-14-00342.1.

5 Berenguer, M., Sempere-Torres, D. and Pegram, G. G. S. (2011) SBMcast - An ensemble nowcasting technique to assess the uncertainty in rainfall forecasts by Lagrangian extrapolation, Journal of Hydrology, 404(3-4), pp. 226240. https://doi.org/10.1016/j.jhydrol.2011.04.033.

6 Caseri, A., Ramos, M.-H., et al. (2016a) A space-time geostatistical approach for ensemble rainfall nowcasting, in 3rd European Conference on Flood Risk Management (FLOODrisk 2016) proceedings. Lyon, France, October 17-21, 2016. https://doi.org/10.1051/e3sconf/20160718001.

7 Caseri, A., Javelle, P., et al. (2016b) Generating precipitation ensembles for flood alert and risk management, Journal of Flood Risk Management, 9(4), pp. 402-415. https://doi.org/10.1111/jfr3.12203.

8 CCR (2019) Les catastrophes naturelles en France, Bilan 1982-2018. Caisse Centrale de Réassurance, p. 100. Available at: https://catastrophes-naturelles.ccr.fr//bilan-cat-nat-1982-2019 (Accessed: 3 March 2021).

9 Charpentier-Noyer et al. (2021) Evaluation of three short-range (0-6h) rain ensemble forecasts: study of the Aude October 2018 flash floods (southeastern France), EGU General Assembly 2021, online, 19-30 Apr 2021, EGU21-11946, https://doi.org/10.5194/egusphereegu21-11946.

10 Collier, C. G. (2007) Flash flood forecasting: What are the limits of predictability?, Quarterly Journal of the Royal Meteorological Society, 133(622), pp. 3-23. https://doi.org/10.1002/qj.29.

11 Corral, C. et al. (2019) Comparison of two early warning systems for regional flash flood hazard forecasting, Journal of Hydrology, 572, pp. 603-619. https://doi.org/10.1016/j.jhydrol.2019.03.026.

12 CRED and UNDRR (2015) The Human Cost of Weather Related Disasters - 1995 - 2015. Centre for Research on the Epidemiology of Disasters ; United Nations Office for Disaster Risk Reduction, p. 30. Available at: https://www.undrr.org/publication/human-cost-weatherrelated-disasters-1995-2015 (Accessed: 3 March 2021).

13 Gourley, J. J. et al. (2017) The flash project Improving the Tools for Flash Flood Monitoring and Prediction across the United States, Bulletin of the American Meteorological Society, 98(2), pp. 361-372. https://doi.org/10.1175/BAMS-D-15-00247.1.

14 Hapuarachchi, H. A. P., Wang, Q. J. and Pagano, T. C. (2011) A review of advances in flash flood forecasting, Hydrological Processes, 25(18), pp. 2771-2784. https://doi.org/10.1002/hyp.8040.

15 Hocini, N. et al. (2021) Performance of automated flood inundation mapping methods in a context of flash floods: a comparison of three methods based either on the Height Above Nearest Drainage (HAND) concept, or on 1D/2D shallow water equations, Hydrology and Earth System Sciences. https://doi.org/10.5194/hess-2020-597.

16 IPCC (2018) Global Warming of $1.5{ }^{\circ} \mathrm{C}$, Global Warming of $1.5^{\circ} \mathrm{C}$. An IPCC Special Report on the 
impacts of global warming of $1.5^{\circ} \mathrm{C}$ above pre-industrial levels and related global greenhouse gas emission pathways, in the context of strengthening the global response to the threat of climate change, sustainable development, and efforts to eradicate poverty. Available at: https://www.ipcc.ch/sr15/ (Accessed: 7 March 2021).

17 Javelle, P. et al. (2016) Setting up a French national flash flood warning system for ungauged catchments based on the AIGA method, in 3rd European Conference on Flood Risk Management (FLOODrisk 2016) proceedings. Lyon, France, October 17-21, 2016. https://doi.org/10.1051/e3sconf/20160718010.

18 Jay-Allemand, M. et al. (2020) On the potential of variational calibration for a fully distributed hydrological model: application on a Mediterranean catchment, Hydrology and Earth System Sciences, 24(11), pp. 5519-5538. https://doi.org/10.5194/hess-24-5519-2020.

19 Le Bihan, G. et al. (2017) The challenge of forecasting impacts of flash floods: test of a simplified hydraulic approach and validation based on insurance claim data, Hydrology and Earth System Sciences, 21, pp. 59115928. https://doi.org/10.5194/hess-21-5911-2017.

20 Lovat, A., Vincendon, B. and Ducrocq, V. (2019) Assessing the impact of resolution and soil datasets on flash-flood modelling, Hydrology and Earth System Sciences, 23(3), $\quad$ pp. $1801-1818$. https://doi.org/10.5194/hess-23-1801-2019.

21 Lovat, A., Vincendon, B., and Ducrocq, V. (in review) Hydrometeorological evaluation of two nowcasting systems for Mediterranean heavy precipitation events with operational considerations, Hydrol. Earth Syst. Sci. Discuss, https://doi.org/10.5194/hess-2020-629.

22 MEDDE (2012) Première évaluation nationale des risques d'inondation, Principaux résultats - EPRI 2011. Ministère de l'Écologie, du Développement durable et de l'Énergie, p. 9. Available at: https:/www.ecologie.gouv.fr/sites/default/files/EPRIPrincipaux-resultats 120712.pdf (Accessed: 3 March 2021).

23 Munich RE (2018) Natural catastrophes 2017, Analyses, assessments, positions, p. 80. Available at: https://www.munichre.com/topics-online/en/climatechange-and-natural-disasters/natural-disasters/topicsgeo-2017.html (Accessed: 8 March 2021).

24 Peredo, D. (2021) Quels gains d'une modélisation hydrologique adaptée et d'une approche d'ensemble pour la prévision des crues rapides ? Thèse de doctorat, INRAE (Antony), Sorbonne Université (Paris), GRNE (Paris), 269 pp.

25 Peredo Ramirez et al. (2021) Investigating hydrological model versatility to simulate extreme flood events, EGU General Assembly 2021, online, 19-30 Apr 2021, EGU21-2984, https://doi.org/10.5194/egusphere-egu212984.

26 Saint-Martin, C., Javelle, P. and Vinet, F. (2018) DamaGIS: A multisource geodatabase for collection of flood-related damage data', Earth System Science Data, 10(2), pp. 1019-1029. https://doi.org/10.5194/essd-101019-2018.

27 Sauvage, C. et al. (2020) Characterization of the air-sea exchange mechanisms during a Mediterranean heavy

${ }^{\text {a }}$ Corresponding author: pierre.javelle@inrae.fr

DOI 10.3311/FLOODRisk2020.17.3 precipitation event using realistic sea state modelling, Atmospheric Chemistry and Physics, 20(3), pp. 16751699. https://doi.org/10.5194/acp-20-1675-2020.

28 Seed, A. W., Pierce, C. E. and Norman, K. (2013) Formulation and evaluation of a scale decompositionbased stochastic precipitation nowcast scheme, Water Resources Research, 49(10), pp. 6624-6641. https://doi.org/10.1002/wrcr.20536.

29 United Nations (2015) Sendai Framework for Disaster Risk Reduction 2015-2030, p. 32. Available at: https://www.undrr.org/publication/sendai-frameworkdisaster-risk-reduction-2015-2030 (Accessed: 8 March 2021). 


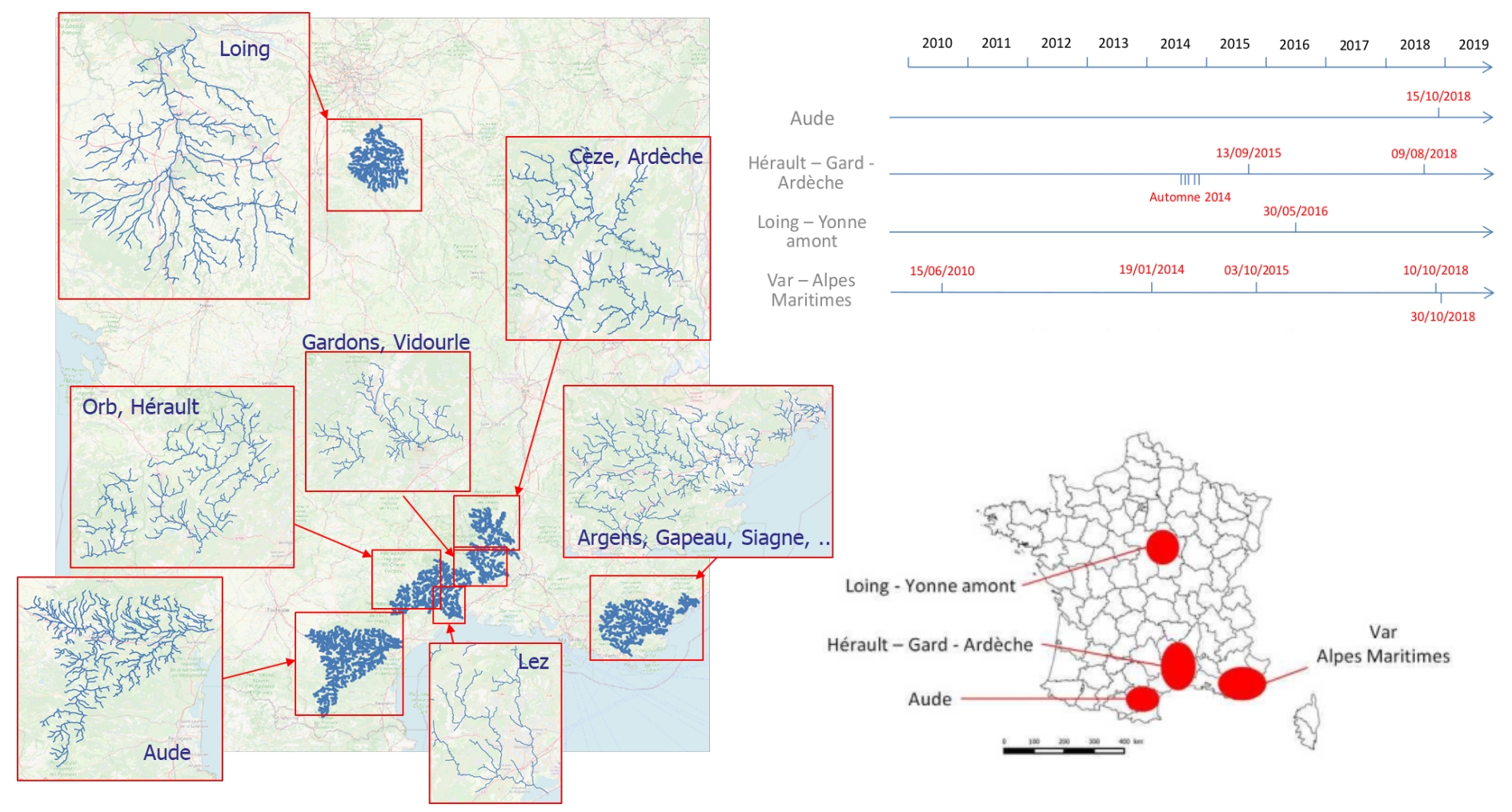

Figure 1. Selected PICS case studies 


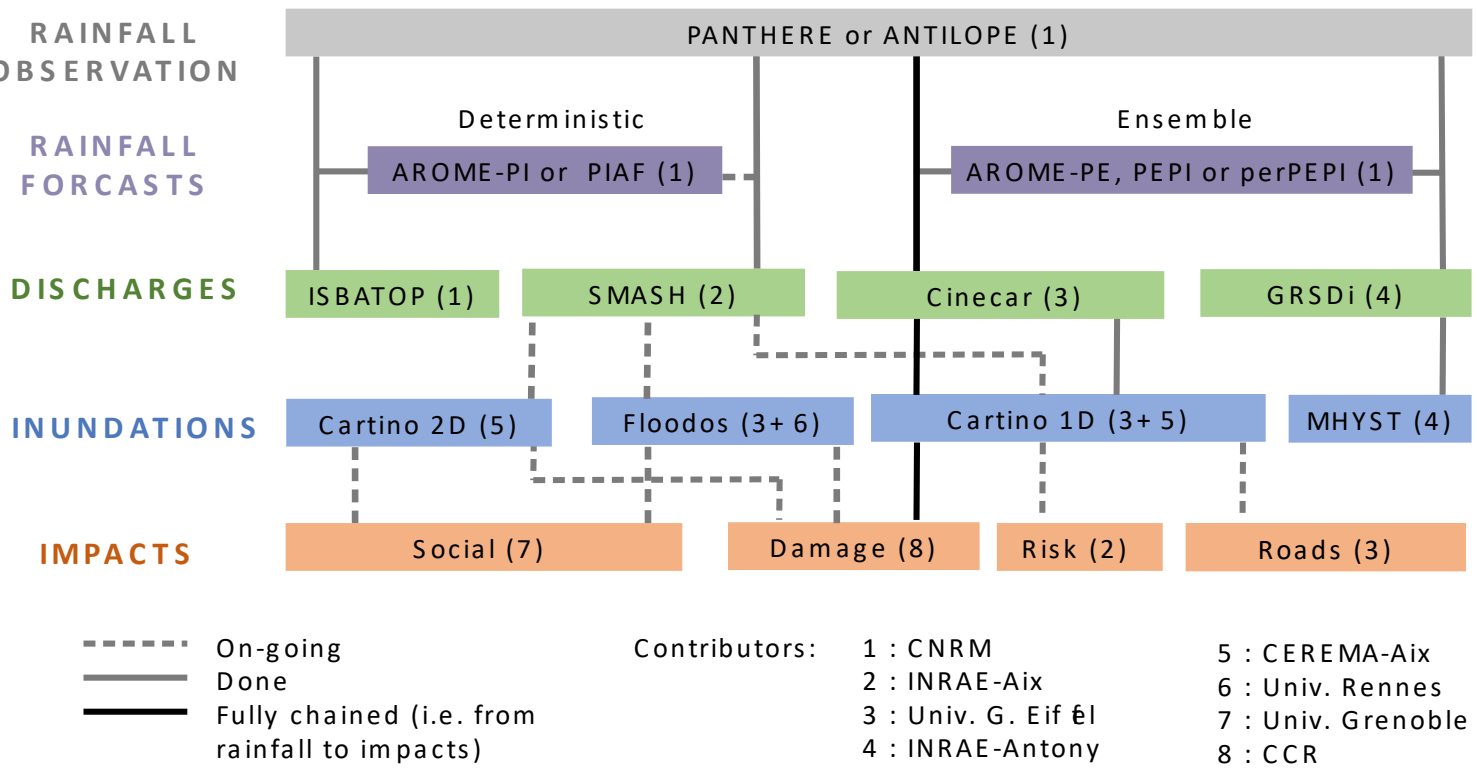

Figure 2. Chained components within the PICS project 


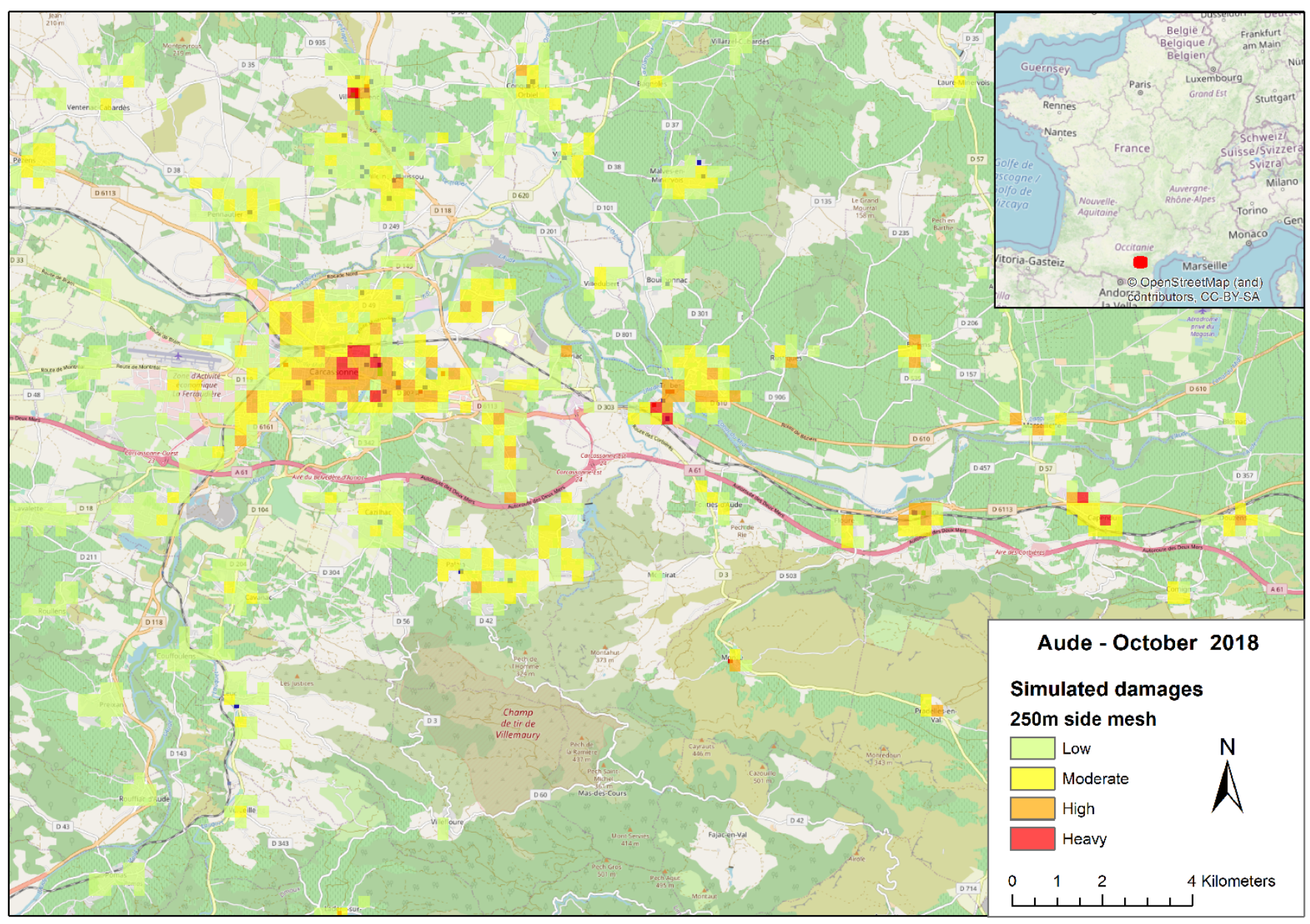

Figure 3. Simulated damage for the 2018 flood around Carcassonne (source: CCR) 